\title{
The black hole in science journalism: A study of journalism students' accommodation strategies of scientific writing
}

\author{
Wincharles Coker \\ Lecturer \\ Department of Communication Studies \\ College of Humanities and Legal Studies \\ University of Cape Coast, Ghana \\ Email:wcoker@ucc.edu.gh \\ Richmond S. Ngula \\ Senior Lecturer \\ Department of English \\ College of Humanities and Legal Studies \\ University of Cape Coast, Ghana \\ Email: rngula@ucc.edu.gh
}

Submitted: November 4, 2019/Accepted: November 20, 2020//Published: January 28, 2021

\begin{abstract}
This study examined strategies employed by journalism students to accommodate scientific communication into public news. Data were collected from news articles of 130 journalism students, 130 science-based research articles, 3,990 minutes of interviews between scientists and trainees, and among 25 focal participants. We found that some journalism students could not adequately accommodate scientific articles into news reports due to their passive knowledge of newswriting journalese. We also observed that journalism students had difficulty in interpreting scientific research claims, and showed less resilience to cope with the angst of scientists about the journalistic profession and the humanities. The paper concluded that the accommodation of scientific communication into public news is a rigorous process that requires the active participation and praxis of journalism students.
\end{abstract}

Keywords: Science journalism, science news, science literacy model, scientist authors, accommodation 


\section{Introduction}

Science journalism, in one respect, may be likened to the black hole in quantum physics. Just like this incredibly compressed space in the universe, science journalism appears to be a no-go area even for many an experienced journalist. One plausible reason for this angst is that the language of the natural sciences is often obtuse because scientific reports belong to the forensic genre which requires that scientists advance arguments to affirm the validity of their claims (Fahnestock, 1998; Murcott \& Williams, 2012; Secko et al., 2013; Barel-Ben et al., 2020). A recent study among journalists in New Zealand, for instance, showed that scientists expressed concerns that journalists sometimes poorly communicated and misrepresented the scientists' research findings to the public (Ashwell, 2016) visà-vis the public's sometimes biased culture of science (MartinSempere et al., 2008; Brossard \& Scheufele, 2013). It is in this context of possible misinterpretation and lack of appreciation of science by consumers in the larger society that scholars have cautioned that the communication of scientific knowledge to the general public via mass media requires a new relationship between the world of science and that of the news media (de Semir, 2000; MacLaughlin et al., 2018). This relationship, we will show in this study, is key to societal development because the news media play an important role in informing and educating the public about scientific and technological developments (Ashwell, 2016, p. 279). A systematic inquiry into how scientific communication, such as the one reported in expert research articles (henceforth RAs), is written as public news by journalists is, therefore, useful.

The starting point of science journalism may be traced to the seventeenth century when scientific research undertakings mainly appeared in newsletter outlets such as the Philosophical Transactions (Jucker, 2009). During these early times, scientists were sharing their new knowledge discoveries with their peers and colleagues in the form of scientific news reports. This 
process birthed a narrowed perspective of scientific knowledge as news, and has shaped the way new knowledge in science is being disseminated today, as research articles in journals, edited volumes, conference collections, research books, etc. The discourse of scientific knowledge, as contained in RAs, in particular, has been reported widely in several volumes of studies, focusing on textual rhetorical practices in RAs (e.g., Verdaguer et al., 2013); ethnographic studies on RA writing (e.g., Curry \& Lillis, 2013); the RA and intercultural rhetoric (e.g., Mur Deuñas, 2007) or the RA and pedagogical instruction.

In this paper, however, we focus on a much broader - but under-researched - perspective of scientific news reports. We explore how new scientific knowledge reported in RAs is further communicated in the mass media as part of news journalists deliver to the general public. Because of the special role of the news media in shaping the world view and opinions of people in any society (Bednarek \& Caple, 2012), there has been in recent years an increasing effort by journalists to either report wholesale scientific research discoveries in specific sections of newspapers and news outlets, or draw on scientific knowledge in their reportage of related news items. Either way, as part of their social responsibility to the public, journalists are expected to regularly engage scientists to be able to present accurate accounts of scientific news (de Semir, 2000; Baren-Ben et al., 2020). A few studies have already been carried out to examine the role of science journalism within the media space, including, for example, Ashwell (2016) and several chapters in the volume edited by Bauer and Bucchi (2007). Most of these studies have focused on how professional journalists have tended to report scientific knowledge to the general public, as well as their roles and challenges as scientific news reporters. There is, however, not much work that examines how journalism students, who would subsequently become professional science reporters, are guided through the process of training and capacity building to take up this task. Yet such studies stand not only to increase 
the attention given to the reporting of scientific knowledge by journalists but also are likely to enhance the quality of work done in this regard.

The present study aimed to fill this lacuna. The objective of the research was two-legged. On the first, we explored the ability, competence, and challenges journalism students faced in accommodating or 'translating' scientific reports into news stories. Examples of challenges encountered by the students included academic pomposity and snobbery, reticence on the part of scientists to be in the public eye, scientists' distrust of journalists for fear of being misquoted, difficulty in explaining scientific jargon, and scientists' reluctance to popularize science and secure uptake for their research. The second objective examined the kinds of strategies the students employed in communicating science news. To do so, we focused on a group of 130 journalism students and the research articles they collected from 130 scientist-authors based in a large public university in Ghana as the data sources to help us address the aims outlined above. The remainder of the paper is structured into five basic sections. Part I attempts to map the literature on two key concepts in the study: scientific communication and the research article. In Part II we offer the concepts of literacy science model and accommodation as the framework for the analysis and interpretation of data. Part III details the interpretive case study employed in conducting the research, and specifies the ethical procedure followed in collecting data. Challenges faced and strategies adopted by journalism students to accommodate students' research findings are discussed in Part IV of the paper. The section also analyzes two samples of news reports written by two journalism students as a way of demonstrating efforts at accommodating scientific communication. The concluding section, Part V, brainstorms the larger significances and implications of the research findings, and makes some suggestions for future research and praxis. 


\section{Scientific journalism and the scientific research article in context}

The body of literature on science communication, in general, and science journalism, in particular, is huge and disparate. Perspectives from media and new media studies (Kua et al., 2004; Brossard \& Scheufele, 2013; Barel-Ben et al., 2020), rhetoric and discourse analysis (Selzer, 1993; Fahnestock, 1998) as well as linguistics (Swales, 2004; Englander, 2006; Hyland, 2016) have all made significant contributions to research in science journalism (Fahnestock, 1998; Bauer \& Buchi, 2007; MacLughlin et al., 2018; Khairy, 2020). Taken together, much of the literature points to growing concerns about how science research, especially in scientific journals, get reported in both traditional and new media. In recent times, researchers have begun to examine the public's response and reception of science news. Researchers have examined the subject from myriad perspectives. Barel-Ben et al. (2020) recently explored the prospects of young career scientists themselves becoming science news reporters, and observed no significant differences in the scientists' reports and their translation of the reports into popular science stories. It is on account of this that the authors believed that it has now become necessary for early career scientists to train and write news about science, as a way of addressing the science news void. Kua et al. (2004) further revealed aspects of the general concern. They looked particularly at how science journalists report genomics in the press and raised a major concern of how the context of the original genomics article in science journals is lost when journalists reported it in news, thereby negatively affecting readers' judgment of the meaning of the science news. They noted that the science reports they studied varied in what they say rather than how they say what they say. This observation made them to conclude that science journalists need to do more to ensure that they are able to translate science into non-science language for public consumption. MacLaughlin et al. (2018) explained that this difficulty may be 
due to the difficulty of the journalists to recognize that textual features significantly improve the accuracy of the prediction over metadata features, with abstract and press release features providing the largest boost in accuracy, just as Yi-Fan $\mathrm{Su}$ et al.'s (2015) study investigated audience's repertoires of science media consumption and how these help reveal consumption patterns on public understanding of science. Other studies also examined how scientists employed new media as a tool in reporting scientific information (e.g., Brossard \& Scheufele, 2013). Essentially, knowledge of the scientific research article (RA) as a genre is key in understanding science journalism.

There is considerable consensus among scholars that the RA represents the most important medium by which new scientific knowledge is disseminated. As Hewings (2001) noted, the RA is "the most important channel for conveying claims of new knowledge" (p. 12). Due to the mammoth role this genre plays in the construction and dissemination of new knowledge, it has been extensively studied (Swales, 2004; Salager-Meyer \& Samraj, 2002). A central concern of these studies has been to draw on the best exemplars of RAs to examine their linguistic, rhetorical, and structural features with a goal to satisfy pedagogical needs, especially in relation to the teaching of English for Academic Purposes (EAP). Some of these studies have been undertaken to explore these features across disciplines in order to show the way disciplines might vary relative to the linguistic and rhetorical features they use.

Amore critical perspective to the study of the RAquestions the role of English as the language of science. It has been strongly suggested that the use of the English language as the language of the RA promotes inequality and bias. This bias, some authors have noted, favors Anglo-American scholars over non-native or multilingual scholars. Some scholars, however, have argued that such concerns have no empirical merit (e.g., Hyland, 2016) and that multilingual scholars need to be made more aware of the linguistic and rhetorical requirements of the English used 
to disseminate scholarly work in Anglophone journals (e.g., Martinéz, 2005; Englander, 2006). There is yet another position on this subject of discrimination against multilingual scholars seeking to write articles for respected Anglophone journals. This position is a liberal and pragmatic one which foregrounds not the perceived injustices against third world scholars but rather the economic, logistic, and technological deprivation most multilingual scholars in third world contexts face makes it difficult for them to meet the publishing demands of what Flowerdew (2001, p. 122) has called "the intellectual centers of the developed countries." Researchers holding this view (e.g., Canagarajah, 2002; Labassi, 2009) think it is better for multilingual scholars in third world contexts to consider ways of improving their linguistic capacity, technological, and resource conditions in order to experience an enhanced visibility of their work in mainstream Anglophone journals.

In brief, the scientific research article, as we have discussed, is one of the most important sources of information available to science journalists in their effort to convey accessible science news stories to the public. In the next section, we turn attention to theories we employed in the study.

\section{Grounding science journalism in theory}

In an effort to further contextualize discussion of our research findings, this section details understanding of two concepts core to the study: literacy science model and accommodation. While the former has received considerable attention in the science journalism literature (e.g. Leweinstein, 2003; Secko et al., 2013; Grand et al., 2015; Khairy, 2020), the latter is a classic articulation of rhetorical and discourse analysis of scientific texts such as news stories. Taken together, they provide a solid foundation for conceptualizing how journalism students try to "break down" expert knowledge to non-initiated audiences.

We begin with the literacy science model. Just as one 
of the four models of science journalism developed by Secko, Amend and Friday (2013), the literacy science model (LSM) seeks to clearly represent how science journalism can be produced and communicated to their audiences. Its goal is to "translate" scientific information for differing publics in order that they may take their right decisions in their daily lives (Secko et al., 2013: 67). This objective makes LSM a pedagogicallyoriented model that pays specific attention at promoting science literacy and the understanding publics have about science. To this end, LSM employs basic journalistic norms such as objectivity via a top-down linear approach to make research and scientific information become accessible news stories. Secko et al. (2013) noted that a story written from the perspective of LSM should attempt to emphasize specific events and publication, and should be written in a traditional information-delivery style (p. 72). The authors stressed that news stories can be accessible to publics when experienced science journalists, whom Polman et al. (2014) described as "competent outsiders," focus on scientific experts as their main sources. This means that LSM, as a journalistic format, builds on the credibility of evidencebased scientific facts, while employing simplified language to complex terminologies (Grand et al. 2015; Khairo, 2020). The model has, however, been accused of disregarding the contextual background through which the publics can relate to the plausible effects of such scientific breakthroughs or diseases on a daily basis; it views audiences as passive spectators of information provided by experts and official reports (Leweinstein, 2003; Secko et al., 2013).

It can be noted, then, that accommodating scientific information into public news is a rhetorical practice. Fahnestock (1998) stressed that the information travels from one rhetorical situation to another. As she put it, "It is undoubtedly true that ... the accommodators of science speak of it more elegantly than the very scientists themselves," and, as such, "communicate where the originators of new knowledge might only confuse" 
(p. 331). When journalists accommodate scientific genres, they seek to bridge the gap between the public's right to know and the public's ability to understand. In other words, to accommodate a scientific piece of information is to attempt to bring the information down to the level of lay audiences just so they may recognize the significance of that information. The rhetorical competence involved here is hinged on two basic principles. One, a shift in genre must occur between the original presentation of a scientist's work and its popularization, and two, this must be accompanied by a change in statement types that occur when a larger audience is addressed. This is because scientific reports such as research articles are, first and foremost, forensic discourses, as they are primarily concerned with establishing the validity of the claims they make (Fahnestock, 1998: 333). The reports are also largely epideictic. These types of scientific information seek to provide current information, the purpose of which is to celebrate rather than validate. In brief, accommodating science involves translating, interpreting, telling and packaging stories from scientific reports for public consumption.

\section{Data and study methods}

Using an interpretive case study design, we collected data among 130 journalism students and 130 research scientists at the University of Cape Coast (UCC), Ghana, between September and December, 2018. Interpretive research is a selfreflexive endeavor that enables researchers to remain open to the biases inherent in knowledge work (Goodall, 2000). We were, therefore, mindful of our ethical conduct in representing our participants, in respect of what, and how we wrote about them. To this end, we engaged in constant member reflections and careful use of pseudonyms to label our focal participants. Member reflections enabled us to regularly dialogue with our research participants about emerging research findings. This methodological posture, according to Tracy (2013), "creates a space for additional insight and validity" (p. 249). To ensure 
that, students returned to the offices of the scientists whose RAs they were working on to discuss with the scientists how they were recomposing the scientists' RAs into accessible popular news. The scientists were mainly faculty from the College of Health and Allied Sciences and College of Agriculture and Natural Sciences. Only 3 students approached faculty at the College of Education Sciences and College of Humanities and Legal Studies. There were more RAs in the natural sciences-i.e. medicine, chemistry, physics, optometry, etc. - than there were in the social sciences, and the humanities. In all, three types of RAs were collected by the students: single, co-authored, and multiple authored. Our interviews with the students revealed four compelling reasons they were interested in the specialized language of the sciences, namely, $(a)$ personal interest/curiosity; (b) clarity and ease of readability, $(c)$ the impact/relevance of the RA on society; and $(d)$ educational value. Table 1 presents the multiple data collected. 
Table 1: Sources of data

\begin{tabular}{||ccl|}
\hline Sample & Sample size & Data type \\
\hline Scientists & 130 & $\begin{array}{l}\text { Research articles } \\
\text { Interviews (face-to-face } \\
\text { telephone; Email) }\end{array}$ \\
Journalism students & 130 & $\begin{array}{l}\text { News reports, interview } \\
\text { transcripts of 3, 9990 } \\
\text { minutes }\end{array}$ \\
Focal participants & 25 & Focus group interviews \\
& & $\begin{array}{l}\text { Participant observation } \\
\text { (approximately 30 hrs: } \\
\text { contact/office hours) }\end{array}$ \\
\hline
\end{tabular}

Source: Field Data (2018)

Data collection was based on a signature assignment given to the students as part of their training in Specialized Reporting, a third-year undergraduate capstone seminar, offered in the fall of 2018 at the Department of Communication Studies of UCC (See Coker, 2018 for a comprehensive discussion on the structure of the program). The seminar focuses on equipping communication students with critical thinking skills necessary for writing specialized reporting beats especially for the press. The seminar aims to prepare them for internships and first jobs in specialized reporting. The course enables students to practice how to report on and evaluate specialized beats such as science, crime/court, investigative, and business/finance reporting. The seminar is based on the assumption that everyday news is inadequate to address the nuanced nature of society. It stresses the relevance of organizational principles like the inverted 
pyramid, hourglass, and circle block styles as well as specific lead types - summary, bullet, narrative, paradox - in reporting scientific/technological, crime, investigative, sports, and business/economic beats. The capstone project assigned to the students in the semester required them to recompose a scientific research article published between 2015 and 2018 by scientists at UCC. Students were expected to translate the RAs into news articles, drawing on any of the following ways of introducing a scientific beat as their summary lead: the bullet, narrative, or paradox lead types.

All 130 journalism students conducted semi-structured interviews, ranging from 10 minutes to 30 minutes with the scientists. The aim of conducting the interviews was to enable the students to get background information on the RAs they were working on. Because the scientists were very busy faculty, the interviews were in the form of face-to-face interactions, audio-tape recording, telephone interviews, and/or interviews via the electronic mail. Further, 25 students (11 males and 14 females) were purposively sampled through the assistance of the course representative. Upon seeking their consent, the focal participants were asked to engage in focus-group interviews with us, where we requested them to reflect on challenges they encountered in dealing with the scientists, and the strategies they employed to accommodate the RAs they worked on. All data collected were analyzed, using a grounded approach that enabled us to identify consistent themes based on the criteria of recurrence, repetition, and forcefulness (Ashwell, 2016), and were constantly checked with almost 30 hours of contact and consultation of sustained participant observation with the students. The news stories of the focal participants were, then, compared with that of a professional journalist and lecturer in the communication department as a way of ensuring a measure of objective interpretation of students' accommodation of the scientific texts. 


\section{Results and discussion}

This analysis of data discussed here is organized into three main strands. The first focuses on the main challenges journalism students faced in working closely with scientists to accommodate the scientists' research reports. These relate to (a) scientists' concerns of possible misinterpretation of research findings by journalism students; $(b)$ scientists' own difficulty in interpreting research findings to the public; (c) scientists' anxiety to go public/seeming fear of journalists; and (d) perception of scientists about the humanities and their lack of cooperation. The second strand is devoted to an analysis of the strategies - online search for technical language, followup interviews with scientists, and self-tutoring - the students employed in accommodating the scientists' RAs into everyday public news. The third strand provides further evidence of the students' accommodation efforts by offering a comprehensive news analysis of the students' news articles.

\section{Science journalism as a black hole: Challenges of journalism students to accommodate scientific communication}

The foremost challenge journalism students faced in accommodating scientific communication was the difficulty scientists had in interpreting their own researches to the students. Our multiple interviews with students showed that they reported difficulty of scientists to clearly interpret their research findings as the most challenging drawback to their reportage. They noted that many scientists faced some challenges in breaking down technical terms into everyday language as a result of the complex nature of the vocabulary (compare with Kua et al., 2004; Mogull, 2011; Polman et al., 2014). This difficulty, we observed, may have arisen because the scientists were being called upon to temporarily move away from their accustomed forensic genre of communication in order that they may converse in everyday, public discourse (Fahnestock, 1986). Belinda, a focal participant, for instance, narrated her lived experience 
in working closely with her scientist on the research article 'Wounds Healing: Contributions from Medicinal Plants and their Phytoconstituents.' According to her, the scientist found it difficult to explain key terminologies such as 'methicillin resistant staphylococci aureus,' 'vancomycin resistant enterococci,' 'hemostasis inflammation,' and 'fibroplasia' in his research article to her. Belinda observed that the scientist at some point in the interview spoke Twi, the dominant local language in Ghana, to enable her to understand the information he wanted to put across. In Fahnestockian terms, one could say that the scientists were not capable of shifting from their accustomed genre. The finding supports the claim by Kua et al. (2004) that what scientists say markedly differ from how they say it in the media.

Analysis of the interview transcripts showed that one other common challenge the scientists encountered in interpreting their studies to the journalism students was their inability to find the common names or popular words used in the local community. In the case of Belinda, she had to use the Internet to find the common names of some of the plants in the scientific RA she was trying to accommodate. She informed us that when she could not find some of the names of the plants online, the scientist assisted her to locate them on campus in order to get their local names from colleagues. An example is Azadiracta indica (commonly known as Neem tree), Chromolaena odorata (Acheampong leaves) and Liliaceaa (aloe vera). 'It was also difficult,' Belinda noted, 'to easily explain to the lay person with diagrams the chemical compounds in the processes of wound healing.'

Available evidence suggested that some of the scientists were deeply concerned about journalism students approaching them to speak on the scientists' works. According to the students, these scientists did not want to go public. Interactions with focal participants showed that a number of scientists were not welcoming upon knowing that they were journalism students. A 
student reported that a scientist angrily inquired how she could possibly understand his work since he conducts his studies in physics and engineering. Our analysis indicated that the scientists' concerns may have been caused by a reasonable level of their seeming distrust of journalism students to successfully understand scientific research. The scientists were of the view that trainees might end up misinterpreting and altering the meaning of their works (see Ashwell, 2016 for similar findings). For example, Brian reported how he was frustrated at the School of Medical Sciences. According to him, some staff and faculty at the medical school were utterly shocked that an undergraduate trainee journalist would request the publication of scientists in the school. He recalled being asked by one member of faculty thus: 'Do you believe a lecturer will give out their publication to you? This work you are doing is for PhD students. Which lecturer even gave you the assignment?' Another focal participant, Ama, also disclosed that a scientist at the School of Nursing and Midwifery she approached was surprised that she intended to recompose his work for a news article. 'I have heard that journalists cause trouble. I hope you will not put me into trouble,' he remarked jokingly, she added, and walked away laughing over how important the fears of the scientist have made her and her colleagues feel.

Students were also concerned about perceptions scientists had about the humanities. According to them, some faculty in the natural sciences did not consider them as serious students capable of conducting real research. They expressed frustrations at some negative attitudes shown them by some scientists. Kweku, for instance, reported that he was literally sacked from a scientist's office while Adjo was reminded that she did not qualify to interview one scientist about the article the scientist had published because she was not as yet a trained journalist. Focal participants also felt that some scientists were not cooperative. The lack of cooperation, they reported, was expressed in many ways including scientists referring them to 
go online and download articles of their choice instead of giving them specific research articles to use for their assignments. In Jo-Ann's experience, some scientists were reluctant to even talk to her immediately she introduced herself as an arts student. 'What do you need a science article for in the humanities,' and, 'do you think you can read a science paper and understand it?' Atanga also noted that some scientists were reluctant to assist him, and claimed that their articles were too scientific to be comprehended by arts students. One of them told him that his article contained a lot of calculations, and that he did not think that an arts student like him was capable of breaking down the formulae to the understanding of the lay person. This finding, therefore, reinforces the difficulties science journalists face in their work including the rapidly growing demands of online publishing, and the expanding role of the PR professional in setting the news agenda (Murcott \& Williams, 2002; Brossard \& Scheufele, 2013).

\section{Accommodation strategies of scientific communication into public news by journalism students}

Our analysis showed that the basic strategy used by journalism students to accommodate scientific articles into popular news was by doing an online search for technical diction. Kekeli, worked on the RA titled 'Electrochemically Roughened Nanoporous Platinum Electrodes for Non-Enzymatic Glucose Sensors' which was published in 2017 by a senior lecturer at UCC's Department of Biochemistry. She noted that the Internet was a useful tool to help her to understand the complex scientific terminologies used in the research, with examples including 'kinetically-controlled electro-oxidation,' 'nanoporous platinum structures,' and 'electrochemically roughening.' Kekeli also downloaded scientific dictionaries from www.pdfdrive.com, Google Playstore and Encyclopedia Britannica to explain these terms. She explained that these resources were instrumental in enabling her to express herself well in the report as breaking these 
complex terms down into simplified sentences and recounting them in such a way that would make her news report readerfriendly to her non-science audience. For example, she noticed that the research article she was trying to accommodate posited that blood-sugar sensor devices used for clinical purposes are usually fraught with challenges, making them difficult to function properly when at differing atmospheric temperatures such as humidity. To find out the validity of this claim, Kekeli conducted online searches to download research articles published years prior to the date of publication of the RA she was working on, so that she could cross-check the information provided in the RA she was accommodating. According to Kekeli, the information showed that adequate research had been conducted from as early as 2005, all suggesting different solutions to the same problem. She informed us that this information gave her the confidence to report the story since novelty is an important element in newswriting.

A number of students also self-tutored. They engaged in follow-up meetings with the scientists of the RAs they sought to accommodate. As has been discussed earlier, most of them were self-motivated by the challenge of the beat, and so were ready to discover things on their own. This was how they requested to meet with scientists whose RAs they were working on. Thrice Jude consulted with a scientist at the School of Allied Health Sciences on the article 'Nucleic Acid Amplification Testing Detects HIV Transfusion Risk in Serologically-Tested Blood Donor Units.' Following a telephone call with the scientist, Jude met with him in his office. He recalled that the scientist, however, instructed him not to audio-tape record their meeting because he feared his voice would be heard on air, but rather stressed that the trainee journalist should write down vital information as he spoke. For Jude, this option was challenging to him because he could not tell the scientist when to pause. He added that his meeting with the scientist was educative. He said the scientist elaborated on one of the key terms in his research: 'Nucleic Acid 
Amplification Testing (NAAT),' which he explained is a very sensitive test that is able to detect the HIV virus at its acute or early stage. Jude observed that the scientist explained that this test is expensive as compared to the traditional way of screening the HIV virus in donor blood during blood transfusion. He also explained to Jude the term 'window period' in HIV contraction as the interval from when the individual contracted the virus to when he or she was detected of carrying the virus.

Like Jude, Naa narrated to us that her consultations with one of the medical scientists were key in understanding the brain behind the discovery of Dissotis rotundifolia. Dissotis rotundifolia is believed to possess innate potentials against the growth of Helicobacter pylori, a causative agent of peptic ulcer. She recalled that the scientist stressed that most doctors use test kits in testing for the presence of $h$. pylori, and that these kits produce negative results though the organism is present in the human body, a process known as 'false-negative.'

\section{Accommodating scientific communication into public news: the case of two news reports}

This case study analyzed processes employed by two students - Nicole and Kwabena - to accommodate the scientific research articles they worked on into reader-friendly public news articles. We did so by drawing on Mencher's (2010) framework for determining a good news story - accuracy, attribution, balance, objectivity, verification, completeness, fairness, and brevity - in order to explore the strengths and limitations of the students' accommodation processes of their individual RAs. Concerns about language use, structure, focus, and sequence were considered. This was, then, followed by a rewriting of the students' news reports by a colleague and professional journalist with the Daily Graphic, arguably Ghana's largest and leading newspaper with a 50, 000 daily circulation (www.graphic.com. gh/about.html). 
Case study 1: Nicole's scientific news report Nicole worked on the research article, "Effects of Fertilization Rate and Water Availability on Peanut Growth and Yield in Senegal (West Africa)," which was published in the Journal of Sustainable Development by scientists from three countries: Ghana, Senegal, and Germany. Fig. 1 presents the details of all the authors and their institutional affiliations.

Journal of Sustainable Development: Vol. 9, No, 6: 2016 Published by Canad 1913-9063 E-ISSN 1913-9071

\section{Effects of Fertilization Rate and Water Availability on Peanut Growth} and Yield in Senegal (West Africa)

Babacar Faye ${ }^{13}$, Heidi Webber ${ }^{2}$, Thomas Gaiser ${ }^{2}$, Mbaye Diop', Joshua D. Owusu-Sekyere ${ }^{4} \&$ Jesse B. Naab $^{5}$

'West African Science Service Center on Climate Change and Adapted Land Use (WASCAL), School of Agriculture, University of Cape Coast, Ghana

${ }^{2}$ Crop Science Group, Institute of Crop Science and Resource Conservation (INRES). University of Bonn, Katzenburgweg 5, D-53115 Bonn, Germany

${ }^{3}$ Institut Sénégalais de Recherches Agricoles (ISRA), Bambey BP: 211, Senegal

${ }^{4}$ Department of Agricultural Engineering, Sehool of Agriculture, University of Cape Coast, Cape Coast, Ghana

${ }^{5}$ West African Science Service Center on Climate Change and Adapted Land Use (WASCAL) Competence Center, Ouagadougou, Burkina Faso

Fig. 1. Title of a research article in crop science

Fig. 2 shows Nicole's effort at accommodating of the RA in Fig. 1 into a news article. 


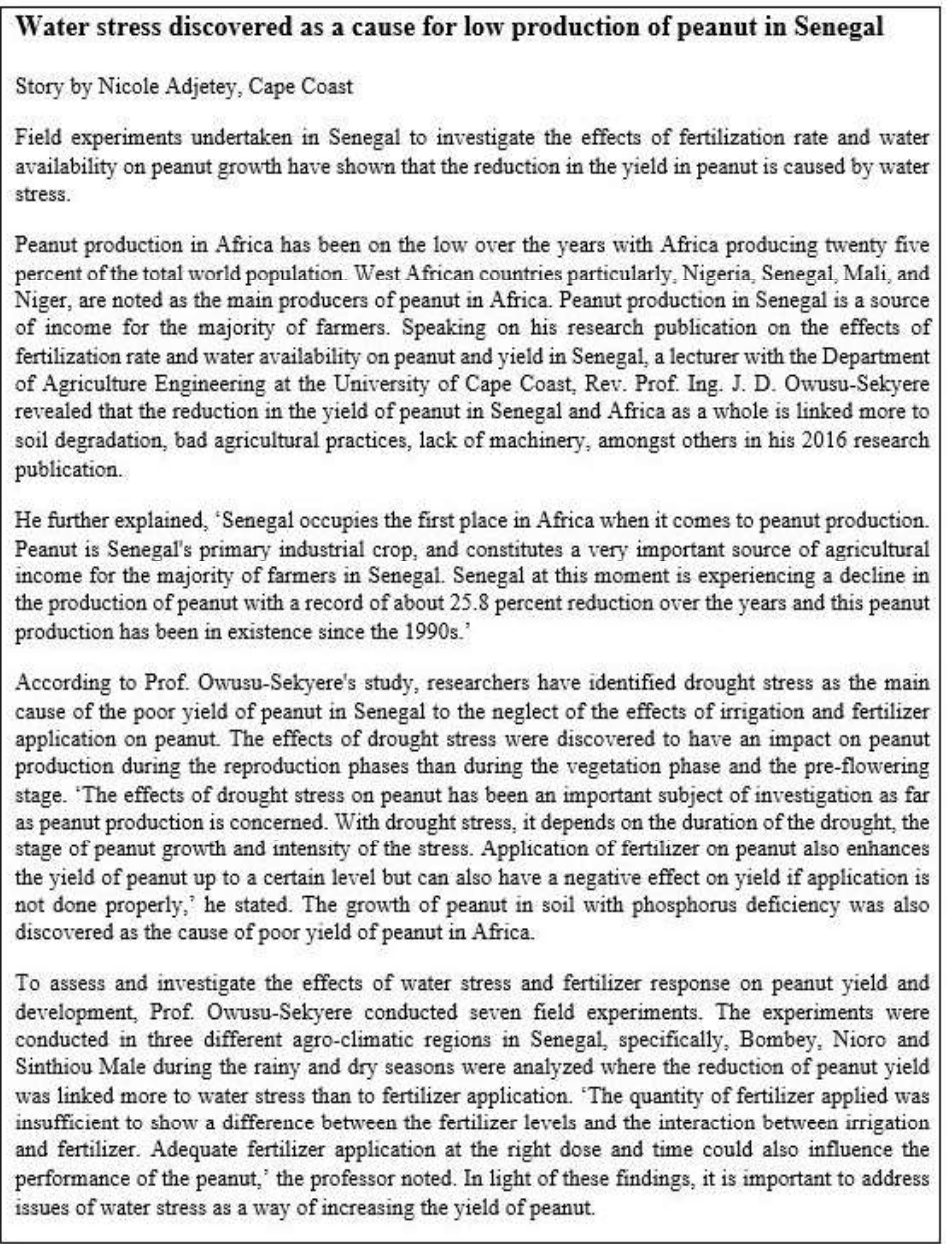

Fig. 2. Nicole's accommodation of the crop science RA into a news article

\begin{abstract}
As can be seen in Fig. 2, Nicole began the story with a good bullet lead by telling readers what might be the most important information in the story. This lead enabled her to focus on the main theme of the story which is about the role of water in peanut cultivation. By starting the story with the most important information, Nicole clearly adopted the inverted
\end{abstract}


pyramid' style as this approach of news writing starts with the most relevant information of the news item (Itule \& Anderson, 2007; Bednarek \& Caple, 2012). Given that the news article was written from a published study, Nicole had little difficulty in balancing different perspectives into her story. Her report was, therefore, fairly objective as there were little signs of bias, prejudice, or personal feeling in the story. One may also note that Nicole's report is brief, and yet contains almost all the basic information found in the original research report from which the story was written.

Despite the tremendous efforts by Nicole to tell readers about what the researchers have done in Senegal concerning water and peanut cultivation, our analysis suggested that there were basic flaws in the story. The sequence of Nicole's report, for instance, is problematic. Sequencing a news report has to do with how ideas in the story are arranged in order to allow the story to flow in the reader's mind. The first issue of sequence can be found immediately after the first paragraph or lead of the story. After telling readers that 'the reduction in the yield in peanut is caused by water stress,' Nicole, in the next paragraph, leapfrogged by going ahead to talk about peanut production in Africa without elaborating how water stress causes peanut yields to decline. Leapfrogging occurs when journalists show little or no link between two consecutive paragraphs (Brooks, 2008; Mencher, 2010). This problem ran through the entire story.

Our study also showed that the fundamental problem in Nicole's report had to do with the lack of completeness in her story. Completeness explains how a writer deals with the six Wh-s in the story, viz., who, what, where, when, why, and how. Basically, journalists ask the question, 'who did what, where, when, and why?' Questions about how the doer did what they did are also important. It is necessary that, in writing a news report, journalists provide answers to fill the gaps of all these elements to make the story complete. We observed that Nicole could not adequately represent who the principal actors in the 
story were. By citing the name of J. D Owusu-Sekyere at the expense of the other five researchers, namely, Babacar Faye, Heidi Webber, Thomas Gaiser, Mbaye Diop and Jesse B. Naab, she unwittingly de-emphasized the collaborative nature of the scientists' project, and in the process, put J. D. Owusu-Sekyere of the University of Cape Coast into prominence or as the lead researcher. This problem may have arisen because he was the only accessible author to have been interviewed by the student. It is also important to note that Nicole could not capture the period within which the study was conducted, that is, between 2014 and 2015 as well as the reasons the scientists advanced for carrying out the study even though it was conspicuous in the RA: "The aim of this study is to assess the effects of fertilizer response and water stress on peanut development, growth and yield in Senegal' (Faye, 2016, p. 112). On the basis of our analysis, we concluded that Nicole could not write a complete scientific news report. Fig. 3 is a suggested improved version of Nicole's news article. 


\section{Water stress discovered as a cause for low production of peanut in Senegal}

Story by Marcelinus Dery, Cape Coast

Field experiments undertaken in Senegal to investigate the effects of fertilization rate and water availability on peanut growth have shown that the reduction in the yield in peanut is caused by inadequate supply of water. In addition, soil degradation, bad agricultural practices, lack of machinery, amongst others have also been found to contribute to declining yield situation in that country.

This was contained in the output of a field research conducted by a team of six agricultural experts in six selected parts of Senegal. The researchers who included a Ghanaian and five foreigners were J.D. Owusu-Sekyere, Babacar Faye, Heidi Webber, Thomas Gaiser, Mbaye Diop, and Jesse B. Naab.

Explaining their choice of Senegal as the site for this study, Rev. Prof. Owusu-Sekyere, the Ghanaian scientist with the University of Cape Coast, said 'Senegal occupies the first place in Africa when it comes to peanut production. Peanut is Senegal's primary industrial crop and it constitutes a very important source of agricultural income for the majority of farmers in that country and the problem of peanut production can better be studied in that country.

He mentioned other African countries which are also into the production of peanut as Nigeria, Mali, and Niger. According to him, the research became necessary because 'peanut production in Africa has been on the low over the years with Africa producing just twenty five percent of the total world production of the commodity.'

He further explained Senegal was experiencing a decline in the production of peanut with a record of about $25.8 \%$ reduction within the past two decades.

Throwing light on their findings, Rev. Prof. J. D Owusu-Sekyere said that the study had identified drought stress as the main cause of the poor yield of peanut in Senegal.

He also cited improper irrigation and fertilizer application methods as some of the factors identified in their study to be contributing to the decline of peanut production in Senegal.

He said they arrived at their conclusion after conducting seven field experiments in three agro-climatic locations in Senegal in different seasons.

Prof. Owusu-Sekyere mentioned the three different agro-climatic locations as Bombey, Nioro and Sinthiou Male adding that the research was conducted during the rainy, and dry seasons.

Fig. 3. A professional journalist's accommodation of the crop science RA

Case study 2: Kwabena's scientific news report

Kwabena sought to accommodate the research article 'Diagnosis and Treatment Outcome of Smear Positive Pulmonary Tuberculosis' published in the Journal of Advances in Medicine and Medical Research in 2018. In one of our informal interviews 
with him, he disclosed that he selected to work on this research report because of its practical impact on society. According to Kwabena, tuberculosis in Ghana 'has become a menace and so I wanted to know how the study has helped in early detection and subsequent treatment and cure with both (TB) single infection and co-infected (TB/HIV) patients.'

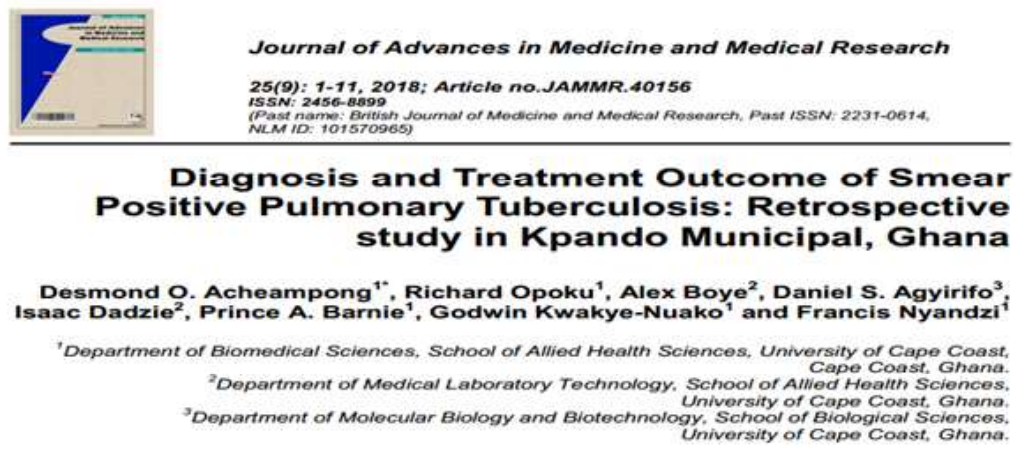

Fig. 4. Title of a research article in medicine

The news article in Fig. 5 is Kwabena's effort to accommodate the RA. 
An analytic view to monitor TB treatment and its success

By Kwabena Obrimpong, Cape Coast

Tuberculosis (TB) is a deadly sickness that has become rampant in our rural areas and also common in most HIV patients. Pulmonary tuberculosis (PTB) refers to any bacteriologically confirmed or clinically diagnosed case of TB involving the lung parenchyma or the tracheobronchial tree. PTB is caused by Mycobacterium tuberculosis is an airborne, contagious disease which primarily affects the lungs and thus transmitted through inhalation of few droplets of tuberculosis (TB) bacilli to cause an infection. There are many ways to identify an infected person and one such method is by having a smear test of the Pulmonary discharge. The purpose of sputum (phlegm) microscopy is to diagnose people with infectious TB, monitor progress of treatment and confirm that total cure has been achieved.

Dr Agyirifo in the past year did a retrospective study with his colleagues seven (7) other postdoctoral fellows who analyses the data collected from entry records in the space of two years (2013-2015) at Anfoega Catholic Hospital in the Kpando Municipal District about smear positive Pulmonary specimens to see how that affect the outcome of treatments. Smear microscopy remains the cornerstone tool for the laboratory diagnosis and in monitoring patients' response to treatment of TB in Ghana and the primary tool for the detection of tuberculosis in Ghana.

The researchers station people in the hospital to collect the data for processing. There arose some challenges with data collection but was overcome. As it is a study of data and not of patients there was ethical freedom but proper approval from administration is given before data is used. The patients are categorized in groups based on their situations like relapse patients, cured patients, treatment failures, treatment success and treatment after failure among others for easy analysis and input in software.

The data by Dr Agyirifo and his colleagues after analysis show that patients with single infection (only TB) are easy to detect as opposed to those who have co-infection (TB/HIV). Previous hospital-based research in Ghana have indicated that prevalence of HIV in TB patients. There data is a total of 116 cases overall of which $56 \%$ are male and $44 \%$ female at the end of their findings, which is either because of the male lifestyle or better immune system of females. With there being a show of TB being prevalent in the youth of Africa so the issue of monitoring and targeting them for the smear test for early detection. As the 116 cases recorded during the study period, $54(46.6 \%)$ was smear positive pulmonary tuberculosis and is highest among 21-40-year group.

The software a statistical package for social sciences (IBM SPSS) windows 20 was easy to use and aided in the simplification of their findings and showed that early detection made patients open to treatment of which they recommended that hospital and healthcare in the rural areas and Ghana as a whole should use the pulmonary smear test concentrating on the youth to easily detect any sign of the tuberculosis bacilli for early treatments we are all ware of the disease now and need to be cured.

Fig. 5. Kwabena's accommodation of the RA in medicine into a news article

Our analysis of Kwabena's news report showed that he first sought to highlight the causes of tuberculosis, its treatment, and prevention. Clarity in language use aside, the report bears a number of noticeable weaknesses. The first is that what Kwabena had written is not a news story but instead an analysis of the 
research report on tuberculosis prepared by the eight academics from the University of Cape Coast. Upon interviewing him, the student admitted that he had trouble distinguishing between reviewing a research report and writing a news report from a scientific research article. In fact, a science news report involves some form of data analysis as the reporter will have to analyze the findings of the research conducted in order to identify newsworthy information therein (see Fahnestock, 1998; BarelBen et al., 2020). Nonetheless, the report written by Kwabena has little news value except for the sentence that reads 'the data by Dr Agyirifo and his colleagues after analysis show that patients with single infection (only TB) are easy to detect as opposed to those who have co-infection (TB/HIV).' It will, therefore, not be useful to subject Kwabena's report to the benchmarks set by Mencher (2010) and others such as Itule and Anderson (2007). Below is a suggested improved version of Nicole's news article. Fig. 6 is a recomposition of Kwabena's work from a professional perspective. 


\section{Scientists discover new treatment for pulmonary tuberculosis}

By Marcelinus Dery, Cape Coast

Tuberculosis (TB) control in Ghana has seen improvements over the years in terms of case notification, case management and overall treatment outcome. Over the last two decades, treatment success rate has increased from $22 \%$ in 1996 to $70.1 \%$ in 2000 , and the figure increased further to $85 \%$ in 2014 .

This is contained in a research paper published by a team of eight academics who conducted a study on TB at Kpando Municipal Hospital from January 2013 to December 2015.

The academics, all of whom are lecturers in the University of Cape Coast, were Desmond $\mathrm{O}$. Acheampong, Richard Opoku, Alex Boye, Daniel S. Agyirifo, Isaac Dadzie, Prince A. Barnie1, Godwin Kwakye-Nuako and Francis Nyandzi.

Diagnosing the disease, a TB skin test was performed by the researchers on patients in order to determine first time exposure to the bacilli.

'This was done by injecting tuberculin into the skin on the lower part of the arm to identify first time exposures,' the researchers stated in the paper.

According to them, 'a chest radiograph was then performed to support diagnosis. Subsequently, an early morning sputum is collected by patient (unless hospitalized) and a spot sputum also collected at site and processed the same day.?

They stated further that "patients were categorized into seven (7) groups. Thus new, old, treated after treatment failure, treated after treatment default, treated after treatment relapse, TB patient with or without HIV, TB patient with or without pulmonary disease/other complications.'

They added that 'sputum microscopy test of tuberculosis was performed using Ziehl Neelsen stain.'

Justifying their choice of diagnosing method, the researchers said 'smear microscopy remains the cornerstone tool for the laboratory diagnosis and in monitoring patients' response to treatment of TB in Ghana. Laboratory diagnosis of active tuberculosis cases by sputum smear microscopy is a critical component of Directly Observed Treatment, Short course (DOTS). The purpose of sputum microscopy is to diagnose people with infectious TB, monitor progress of treatment and confirm that total cure has been achieved.'

They said after they had put control measures in place, "a case of pulmonary TB was classified as positive (confirmed case of PTB) if at least one of the two two/three smears from the two/three sputum specimen received was acid fast bacilli positive and quantified as being scanty, $1+, 2+$ and $3+$ AFB present.'

The researchers attributed the progress made in TB control in Ghana to the effective efforts of the National Tuberculosis Program and the commitment of other NGOs to eradicate TB in the country."

Fig. 6. A professional journalist's accommodation of the medical RA into a news article

\section{Conclusion}

The study suggested that science journalism education can be likened to black holes. Our analysis showed that its practice among journalism students is fraught with a number 
of challenges. In particular, efforts by students in a Ghanaian university to accommodate scientific research reports into popular news stories were met with four main difficulties. These are (1) academic pomposity and snobbery; (2) reticence on the part of scientists to be in the public eye, and their reluctance to popularize science and secure uptake for their research; (3) distrust of journalists on the part of scientists (fear of being misquoted, etc.), and (4) difficulty in explaining technical terminology. Essentially, the study revealed that the journalism students' knowledge of science journalism is processual, and, therefore, work in progress. A principal reason is that students had to grapple with technical communication accessible in specialized journals that are outside of their immediate purview as a result of their humanities-based education. Using online search engines, consulting with scientists for in-depth explanations, and seeking clarifications from scientists were useful strategies to accommodate the forensic nature of scientific communication into reader-friendly public news. We observed that journalism students, however, had to overcome the challenges of misinterpreting claims and research findings contained in the scientific reports, cope with the angst of scientists about the journalistic profession as well as the negative perceptions of some scientists about the humanities as a discipline. In-depth analyses of news reports written by the trainees also showed that a number of them could not adequately accommodate their scientific reports into news reports as a result of their inability to draw on the journalese of newswriting.

The findings of the study have implications for further research in science journalism. There is the urgent need to train scientists to be better communicators with the public. Mogull (2011), for instance, has urged technical communication scholars to design new courses to train scientists as effective communicators in contemporary government and business settings. The study is also of mammoth importance for the promotion of interdisciplinary collaboration. It seeks to bridge 
the sharp binary that has existed between the so-called natural sciences and social sciences.

\section{Acknowledgements}

The authors express gratitude to all anonymous reviewers and the research scientists who consented to the use of their research articles for this study. Thanks also go to Marcelinus Dery of the Department of Communication Studies, University of Cape Coast, Ghana, for his help in recomposing samples of students' news articles, and all third-year communication students of fall 2018 for their role as participants in the research. 


\section{References}

Ashwell, D. J. (2016). The challenges of science journalism: The perspectives of scientists, science communication advisors and journalists from New Zealand. Public Understanding of Science. 25 (3), 379-393.

Barel-Ben, D. Y., Garty, E. S. \& Baran Tsabari, A. (2020). Can journalists fill the science journalism void? Online public engagement with science stories authored by scientists. PLS ONE, 15 (1), 1-15.

Bauer, M. W., Bucchi, M., (Eds.). (2007). Journalism, science, and society: Science communication between news and public relations. Routledge: New York.

Bednarek, M., Caple, H. (2012). News discourse. Continuum Discourse Series: New York.

Brooks, B. S. (2008). News reporting and writing ( $9^{\text {th }}$ ed.). New York: Bedford/St. Martin's.

Brossard, D. \& Scheufele, D. (2013). Science, new media, and the public. Science, 339, 40-41.

Canagarajah, S. A. (2002). A geopolitics of academic writing. Pittsburgh, PA: University of Pittsburgh Press.

Coker, W. (2018). The governmentality of practice in journalism education in Ghana. Legon Journal of the Humanities. 29(1), 132-161.

de Semir, V. (2000). Scientific journalism: Problems and prospects. International Microbiology,3, 125-128.

Englander, K. (2006). Revision of scientific manuscripts by nonnativeEnglish-speaking scientists in response to journal editors' criticism of the language. Journal of Applied Linguistics, 3 (2), 129-161.

Fahnestock, J. (1998). Accommodating science: The rhetorical life of scientific facts. Written Communication. 15(3), 330-350.

Faye, B., Webber, H., Gaiser, T., Diop, M., Owusu-Sekyere, J. D. \& Naab, J. B. (2016). Effects of fertilizer rate and water availability on peanut growth and yield in Senegal (West Africa). Journal of Sustainable Development, 9(6), 111-131.

Flowerdew, J. (2001). Attitudes of journal editors to nonnative speaker contributions. TESOL Quarterly, 35(1), 121-150.

Goodall, H. L. (2000). Writing the new ethnography. AltaMira Press: New York.

Grand, A., Davies, G., Holliman, R., \& Adams, A. (2015). Mapping public engagement with research in a UK university. PLOS One, 10(4), e0121874. doi:10.1371/journal.pone.0121874.

Hewings, M., (Ed.) (2001). Introduction. In: Academic writing in context: Implications and applications (pp. 9-16). The University of Birmingham Press: Birmingham.

Hyland, K. (2016). Academic publishing and the myth of linguistic disadvantage.Journal of Second Language Writing, 31, 58-69. 
Itule, B. D., \& Anderson, D. A. (2007). News writing and reporting $\left(7^{\text {th }} \mathrm{ed}\right)$. McGraw-Hill: Boston.

Jucker, A. H. (2009). Newspapers, pamphlets and scientific news discourse in Early Modern Britain. In: Jucker, A. H. (Ed). Early modern English news (p. 1-9). Amsterdam: John Benjamins.

Khairy, L. (2020). Applying the four models of science journalism to the publics' interaction with coronavirus news. Arab Media \& Society. https://www.arabmediasociety.com/applying-thefour-models-of-science-journalism-to-the-publics-interaction-withcoronavirus-news-in-egypt

Kua, E., Reder, M. \& Grossel, M. J. (2004). Science in the news: A study of reporting genomics. Public Understanding of Science, 13, 309-322.

Labassi, T. (2009). Periphery non-Anglophone scholarship in English-only journals: conditions of a better visibility. Changing English: Studies in Culture and Education. 16(2), 247-254.

Lewenstein, B. V. (2003). Models of public communication of science and technology. Public Understanding of Science, 1-8.

Martin-Sempere, M. J., Garzon-Garcia, B. \& Rey-Rocha, J. (2008). Scientists' motivation to communicate science and technology to the public: surveying participants at the Madrid Science Fair. Public Understanding of Science, 17, 349-367.

MacLaughlin, A., Wihbey, J. \& Smith, D. A. (2018). Predicting news coverage of scientific articles. Association for the Advancement of Artificial Intelligence, np.

Mencher, M. (2010). Mencher's news writing and reporting (11 $\left.{ }^{\text {th }} \mathrm{ed}.\right)$. McGraw-Hill: Boston.

Mogull, S. A. (2011). A call for new courses to train scientists as effective communicators in contemporary government and business settings. In: J. Conklin, J., Hayhoe, G., (eds.), Qualitative research in technical communication (pp. 189-211). Routledge: New York.

Murcott, T. H. L. \& Williams, A. (2012). The challenges of science journalism in the UK. Progress in Physical Geography. 37(2), 152160.

Polman, J. L., Newman, A., Saul, E. W. \& Farrar, C. (2014). Adapting practices of science journalism to foster science literacy. Science Education, 98, 766-791.

Secko, D. M., Amend, E. \& Friday, T. (2013). Four models of science journalism: A synthesis and practical assessment. Journalism Practice, 7(1), 62-80.

Selzer, J. (1993). Understanding scientific prose. University of Wisconsin Press: Madison, WI.

Swales, J. (2004). Research genres. Cambridge: Cambridge University Press. 
Tracy, S. J. (2013). Qualitative research methods: Collecting evidence, crafting analysis, communicating impact. Wiley-Blackwell: Malden, MA.

Verdaguer, I., Laso, N. J. \& Salazar, D., (Eds). (2013). Biomedical English: A corpus-based approach. John Benjamin: Amsterdam.

Woloshin, S. \& Schwartz, L. M. (2002). Press releases: Translating research into news. Journal of the American Medical Association, 287(21), 2856-2858.

Yi-Fan Su, L., Brossard, D., Akin, H., Scheufele, D. A. \& Xeno, M. A. (2015). Science news consumption patterns and their implications of public understanding of science. Journalism and Mass Communication Quarterly, 1-20. 